\title{
Fatigue crack closure: from LCF to small scale yielding
}

\author{
R. Pippan, W. Grosinger \\ Erich Schmid Institute of Material Sciences of the Austrian Academy of Sciences, Jabnstraße 12, A-8700 Leoben, Austria \\ reinhard.pippan@oeaw.ac.at
}

\begin{abstract}
Crack closure has been one of the research topics in the 1980ies and 1990ies. A vast number of papers have been published in this area. However, most of the research work has been devoted to crack propagation under small scale yielding. In this presentation, the different length scale from micro-crack to long cracks and different loading conditions (from low cycle fatigue, LCF, to small scale yielding) affecting crack closure and as a consequence, the near crack tip stress and strain fields are considered. The main focus is on LCF crack closure behaviour which is studied by in-situ scanning electron microscopy. The results demonstrate the importance of crack closure for the explanation of the LCF behaviour. The change of crack closure from LCF to high cycle fatigue and their consequences for lifetime prediction will be discussed.
\end{abstract}

KEYwORDS. Crack closure; Low cycle fatigue; Small scale yielding; Micro-cracks; Long cracks

\section{INTRODUCTION}

$\mathrm{F}$ atigue crack propagation in ductile metals is caused by cyclic plastic deformation at the crack tip, which is governed by the plastic properties of the material and the crack driving force, the stress intensity range $\Delta \mathrm{K}$ or the cyclic $J$ integral. The discovery by Elber [1] of the premature contact of the crack faces in the unloading sequence can reduce the cyclic plastic deformation and therefore the crack propagation rate. This reduction in cyclic plastic deformation can be expressed by a reduction in the local driving force. Hence, one has to distinguish between the applied force and the local driving force or in the case of crack closure it is called the effective driving force (e.g. $\Delta \mathrm{K}_{\text {eff). Plasticity-induced crack }}$ closure, roughness induced crack closure and corrosion debris-induced crack closure (often called oxide-induced crack closure) are considered to be the three most important mechanisms responsible for premature fracture surface contact. Despite the vast amount of studies (see for example [2-11]), there are many unsolved essential questions, for example how does them oxide-induced crack closure in a material depend on crack growth rate, stress ratio, $\mathrm{R}$, environment or temperature, or how can one predict the contribution of roughness-induced crack closure for a certain microstructure as a function of $\Delta K$ and $R$ ? Important to note is that nearly all these studies are devoted to fatigue crack propagation under small scale yielding. There are few studies related to short cracks at notches [12-14], where, however also small scale yielding is dominant.

In the present study crack closure at the other extreme - low cycle fatigue - will be investigated. The importance of closure in this regime will be considered and the change of closure from low cycle fatigue to high cycle fatigue, and finally to small scale yielding will be discussed. The basis for the analyses will be in-situ experiments performed in the scanning electron microscope to determine the crack propagation mechanism, crack tip deformation (i.e. strain fields) and to investigate the crack closure behaviour.

\section{DO SHORT FATIGUE CRACKS PROPAGATE BY A DIFFERENT MECHANISM?}

$\mathrm{P}$

lotting the propagation rate of short fatigue cracks in a standard $d a / d N$ versus $\Delta K$ diagram shows often significant deviations from the long crack data, see for example $[9,15,16]$. Reasons for the differences are the changes in 
crack tip shielding, the non applicability of small-scale yielding parameters or the difference between the micromechanical response and assumed homogeneous material behaviour. Depending on the responsible mechanisms, one can distinguish, therefore, physically (or extrinsically), mechanically and microstructurally short cracks [9, 10, 15]. A fundamental question remains usually open do short cracks propagate by a different intrinsic mechanism? In order to answer this question for a ductile material, the austenitic steel A220 (a modified 316L), short crack experiments are performed in-situ in a SEM and compared with the long crack behaviour described in [17]. The used samples are depicted in Fig. 1. A short notch is machined by a razor blade polishing technique at the corner of the sample. A cut with the focused ion beam at the root of the notch generates a short crack-like defect. Samples with notch depth between 30 and $140 \mu \mathrm{m}$ are investigated. The samples are loaded with constant displacement amplitude. Due to the hour glass contour of the sample, an accurate determination of the applied far field strain from the load versus cross head displacement is not possible. A determination of the applied far field strain amplitude from the SEM images taken at the maximum and the minimum load exhibits a plastic strain amplitude, $\Delta \varepsilon_{\mathrm{p}}$, of about $6 \%$, for the case depicted in Fig. 2, 3 and 5 . At different load cycles at the maximum load and for few selected cycles SEM micrographs at certain loads during loading and unloading are taken from the crack tip. An example is presented in Fig. 2 and 3. It shows that the crack at the minimum load is closed. During the loading the crack blunts and re-sharpens during unloading. The cyclic crack tip opening is therefore equal to the crack tip opening at maximum load, i.e. CTOD $=\triangle \mathrm{CTOD}$ as in the case of steady state propagating long cracks [18]. In Fig. 4 the measured $\triangle C T O D$ are plotted as a function of the crack growth rate. The data obtained from [17], where the samples had a crack length of about $30 \mathrm{~mm}$ are also indicated. It is evident that the crack propagation rate is about one-fourth of $\Delta C T O D$ independent of the crack length or notch depth. In this diagram also data obtained at somewhat smaller strain amplitudes are indicated. The long crack experiments were performed under well-defined small-scale yielding conditions, whereas the short crack experiments are in the extreme low cycle fatigue regime. Despite this difference the relation between $\Delta C T O D$ and $d a / d N$ is not affected. On the contrary, in the standard $d a / d N$ versus $\Delta K$ diagram the difference between the long and short crack data is huge (see [17]).

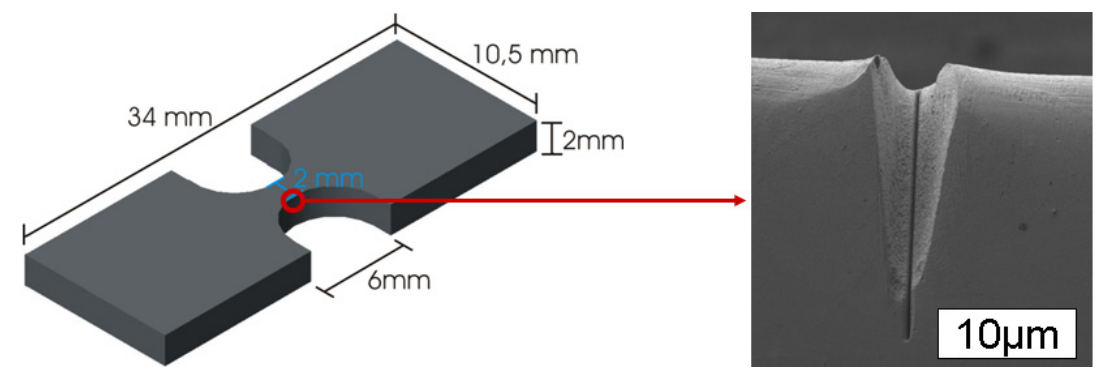

Figure 1: Illustration of the sample geometry for in situ short crack examination and the SEM image of the typical used notch.

The grain size of the austenitic steel A220, used for the short crack experiments in Figs. 2, 3 and 4 is about $10 \mu$ m. Therefore, the investigated cracks are microstructurally long and mechanically and extrinsically short. Similar experiments are also performed in very coarse-grained A220 steel with a grain size of few millimetres [19]. The results are very similar, only the scatter was larger. One of the reasons for this large scatter is the uncertainty in the correct determination of $\triangle C T O D$ and $d a / d N$, which is induced from strong mixed mode loading, pronounced crack branching and crack deflections of the crack in the first grain. The determination of CTOD of a stage I like crack is more difficult than for a well-defined stage II case as shown in Fig. 2. Furthermore it has to be noted that a plastic deformation of the crack flanks somewhat behind the crack tip can cause an opening of the crack but no crack extension, as discussed in [17]. Hence, one has to distinguish between crack tip opening, which generates new fracture surface at the crack tip and a part of the CTOD, caused by the cyclic deformation of the crack flanks in the vicinity of the crack tip. For the determination of CTOD in Fig. 4 we used the definition of CTOD of Ref. [20], this is a good approximation for the deformation direct at the crack tip, which generates new fracture surfaces for a mode I crack in a ductile material. The described experimental results indicate that short and long cracks in ductile metals propagate by the same mechanism, as illustrated in. Hence, for life time prediction, one only has to find the appropriate driving force to describe $\Delta C T O D$. In the case of small-scale yielding, $\Delta K$ or $\Delta K_{\text {eff }}$ and for large-scale yielding $\Delta J$ or a corresponding effective cyclic $J$-integral, $\Delta J$ Jeff are the standard fracture mechanics parameters. 


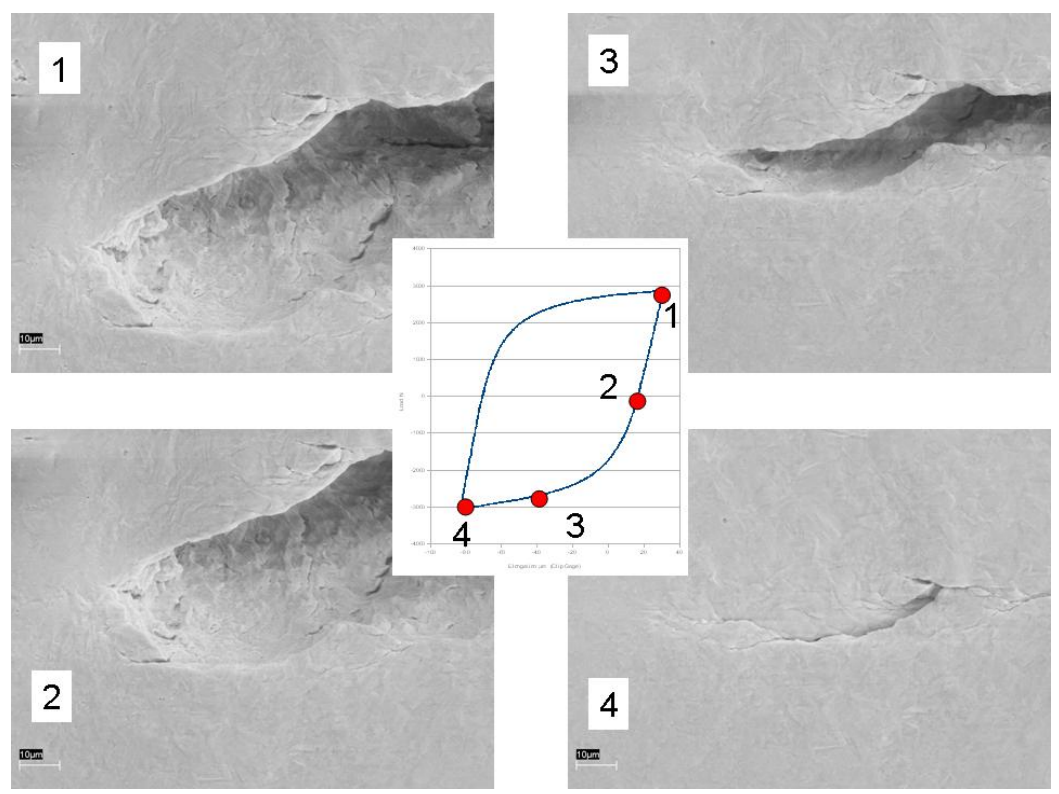

Figure 2: Load-displacement curves of a fatigue experiment and selected SEM micrographs of the crack tip during the unloading cycle. The loads, where the micrographs are taken, are indicated in the load displacement curve.

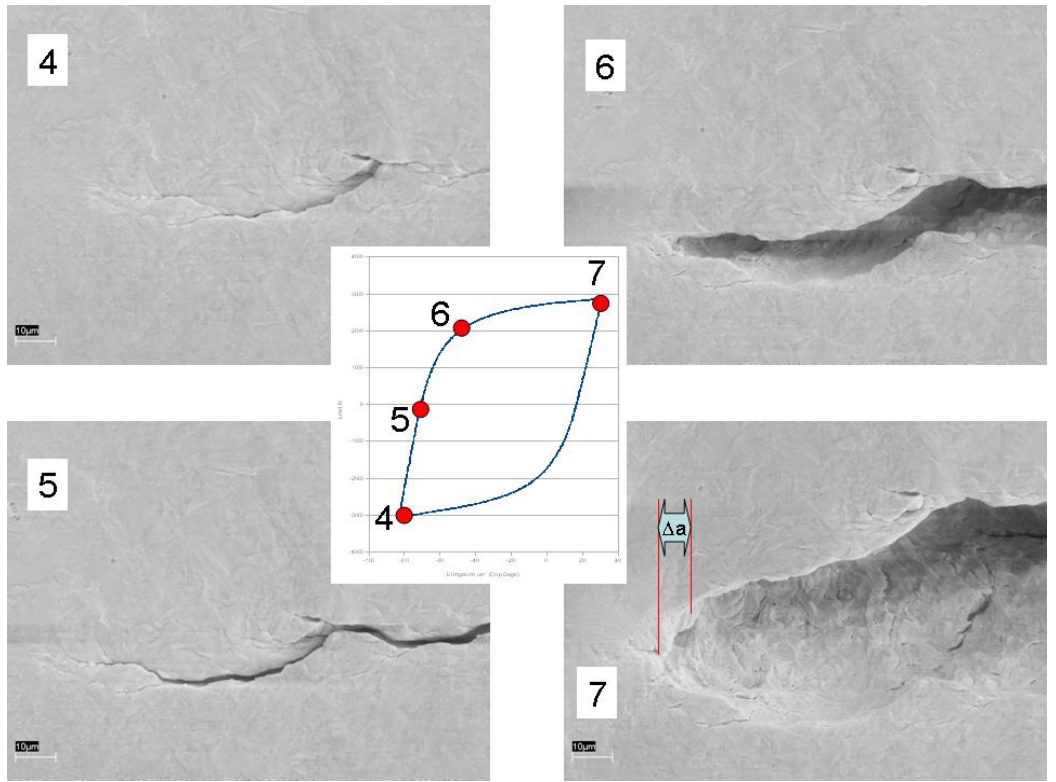

Figure 3: Load-displacement curves of a fatigue experiment and selected SEM micrographs of the crack tip during the loading cycle (continuation of Fig.2). The loads, where the micrographs are taken, are indicated in the load displacement curve.

As a consequence, the low cycle fatigue life time, i.e. the Manson-Coffin relation, Eq. (1) and Refs [21, 22].

$$
\Delta \varepsilon_{\mathrm{p}} / 2=\operatorname{const}\left(N_{f}\right)^{c}
$$

should be describable in terms of crack propagation and should follow from an integration of the crack growth curve. For a semicircular surface crack $\Delta J$

$$
\Delta J \approx 3.2 \Delta W_{e} a+5 \Delta W_{p} a
$$


where $\Delta W_{e}$ and $\Delta W_{p}$ are the elastic and plastic components of the remote strain energy density ranges[24, 25]. $\Delta J$ and $\triangle$ CTOD for an open crack are proportional

$$
\Delta \mathrm{CTOD}=d_{n} \Delta J / 2 \sigma_{y}
$$

where $d_{n}$ is a parameter depending on strain hardening and the ratio of the yield stress, $\sigma_{y}$, to the Young's modulus.

For low cycle fatigue experiments with very large $\Delta \varepsilon_{\mathrm{pl}}$ the elastic component is small, for elastic ideal plastic material $W_{\mathrm{pl}}=$ $2 \sigma_{y} \cdot \Delta \varepsilon_{\mathrm{pl}}$ and $d_{n}=0.8$, therefore $\Delta \mathrm{CTOD} \approx 4 \Delta \varepsilon_{\mathrm{pl}} \cdot a$. The number of cycles to failure, $N_{f}$, is then given by the integration of the growth from an initial flaw size to a critical value. Taking into account that crack propagation rate is proportional to $\Delta \mathrm{CTOD}$ and using Eq. (4) leads to $d a / d N$ proportional to $\Delta \varepsilon_{p l} \cdot a$. In such case the number of cycles to failure should be about inverse proportional to $\Delta \varepsilon_{\mathrm{p}}$. However, it is well known that the Manson-Coffin exponent is significantly smaller than 1 (typically between 0.5 and 0.7 ). One of the reasons for the deviation is that the change of the critical crack length at different plastic strain amplitudes are not taken in to account.

A more accurate estimation gives that $N_{f}$ should be proportional to $\ln \left(a_{\max } / a_{0}\right) / \Delta \varepsilon_{\mathrm{p}}$, where $a_{0}$ is the initial flow size and $a_{\max }$ is the maximum length of the crack in fatigue. However, in most cases $\ln \left(a_{\max } / a_{0}\right)$ is not strongly affected by $\Delta \varepsilon_{\mathrm{pl}}$.
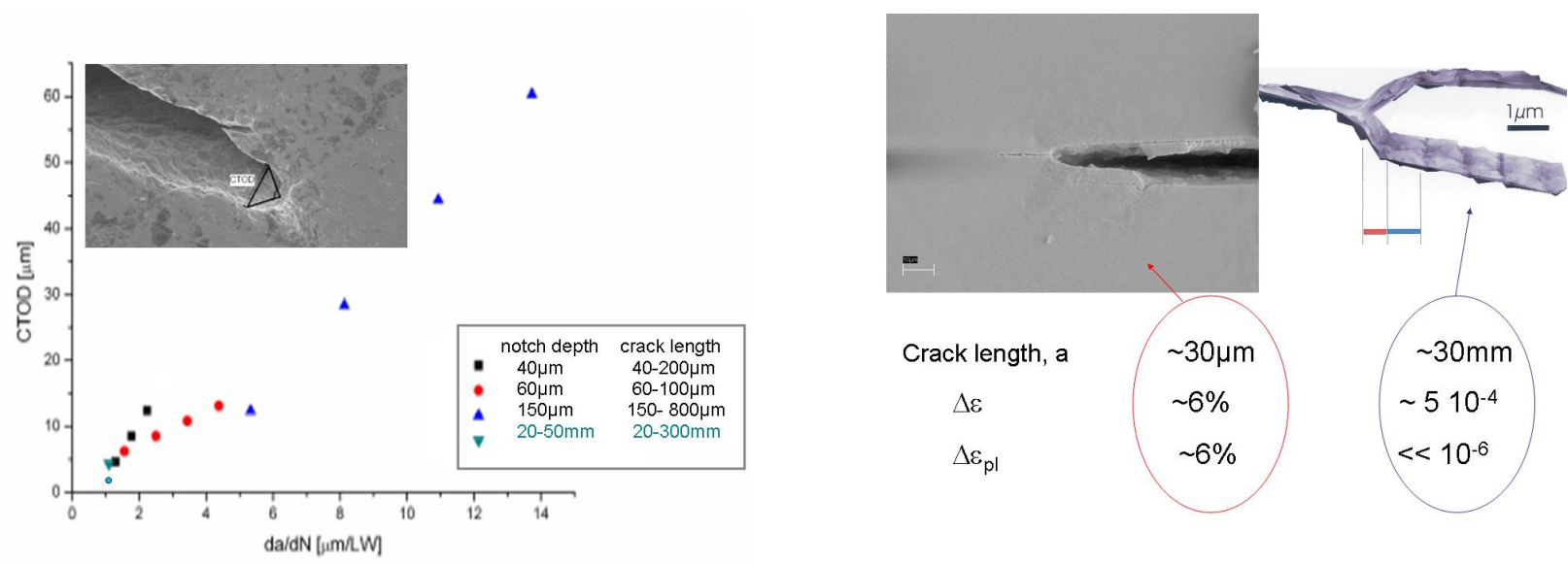

Figure 4: (Left graph) CTOD determined from the SEM micrographs at different crack propagation rate at samples with different depth of micro-notches and different crack lengths. For comparison, the long crack data determined in the same steel in a coarsegrained cold-rolled conditions are also indicated [17]. The right images should illustrate that cracks under extreme different loading conditions (short and long cracks) propagate with the same rate when the crack tip opening displacement is equal.

\section{IS CRACK CLOSURE IMPORTANT FOR MECHANICALLY AND MICROSTRUCTURALLY SHORT CRACKS ?}

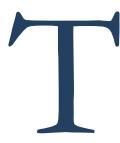
he main reason for the deviation from above described simple estimation is that $\Delta J$ or $\Delta \varepsilon_{\mathrm{pl}}$ is applicable only to describe $\triangle \mathrm{CTOD}$ for cracks which are open during the complete part of the load cycle. Otherwise one has to use $\Delta J_{\text {eff }}$. Not the full amplitude $\Delta J$ or $\Delta \varepsilon_{\mathrm{pl}}$ only a smaller part $\Delta J_{\text {eff }}$ or $\Delta \varepsilon_{\mathrm{pl}}$ eff , are responsible for the observed $\triangle C T O D$. The contact of fracture surface before the minimum of strain is evident from the SEM micrographs in Fig. 5. It is evident that the crack closes near the minimum load, however the crack is closed over a significant part of the strain amplitude. One may argue that during the closed phase of the strain amplitude, there may happen also a significant deformation at the crack tip.

Therefore, incremental strain maps have been determined during loading and unloading from SEM micrographs similar as depicted in Figs. 2 and 3 [17, 23]. The importance of crack closure is clearly visible if one considers the incremental strain maps determined during the unloading part of a load cycle in Fig. 6. In each of the load steps during unloading, the typical localization of the deformation in the vicinity of crack tip is visible; however, in the last load step (near the minimum load) the characteristic deformation pattern near the crack tip vanishes. This clearly indicates that during this part of the loading cycle the characteristic localisation of the strain near the crack tip disappear. In the present example $\Delta J_{\text {eff }}$ is about $80 \%$ of $\Delta J$. An essential point to describe the low cycle fatigue behaviour in terms of fracture mechanics is, therefore, to predict 
the effective driving force as a function of $\Delta \varepsilon_{\mathrm{pl}}$ and the loading history. In constant $\Delta \varepsilon$ or $\Delta \varepsilon_{\mathrm{pl}}$ experiments, the effective $\Delta J$ or $\Delta \varepsilon_{\mathrm{pl}}$ should decrease substantially as schematically depicted in Fig. 7 with decreasing $\Delta \varepsilon_{\mathrm{pl}}$. This should be a main reason for the deviation from above estimated Manson-Coffin exponent and the different transition behaviour from LCF to HCF.

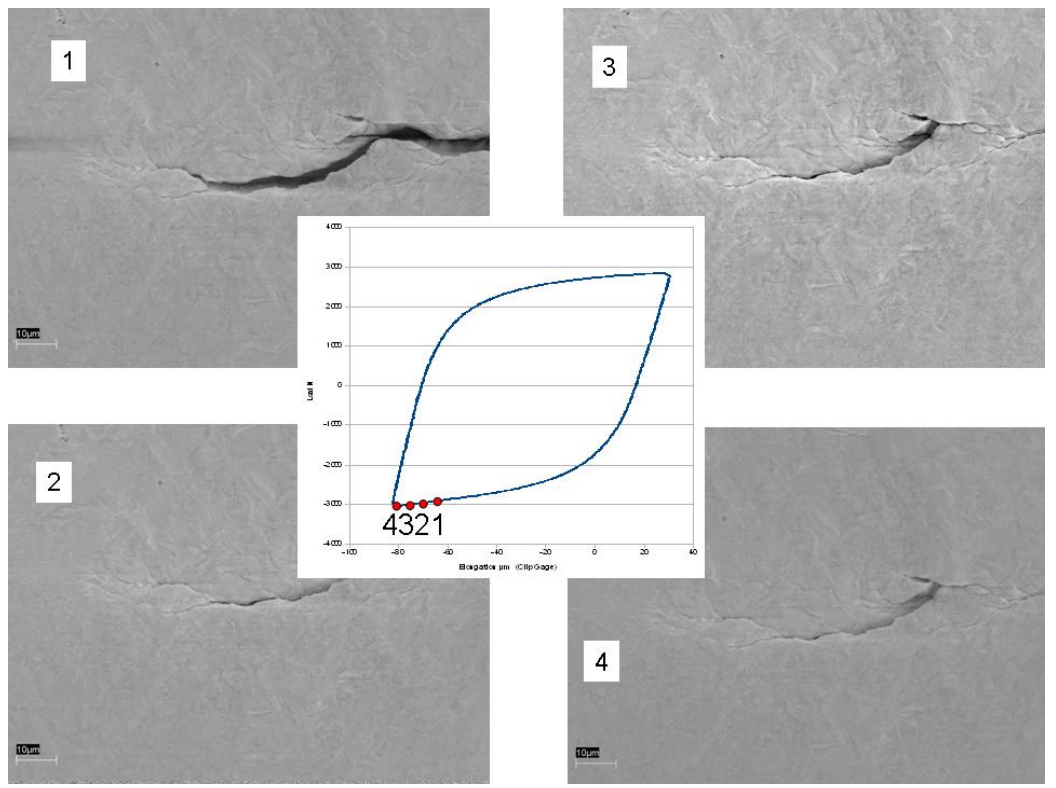

Figure 5: Load-displacement curves of a fatigue experiment and selected SEM micrographs of the crack tip during the end of the unloading cycle which shows the details during closing of the crack. The loads, where the micrographs are taken, are indicated in the load displacement curve. The Figure should illustrate that the crack is closed during a certain part of the strain amplitude.
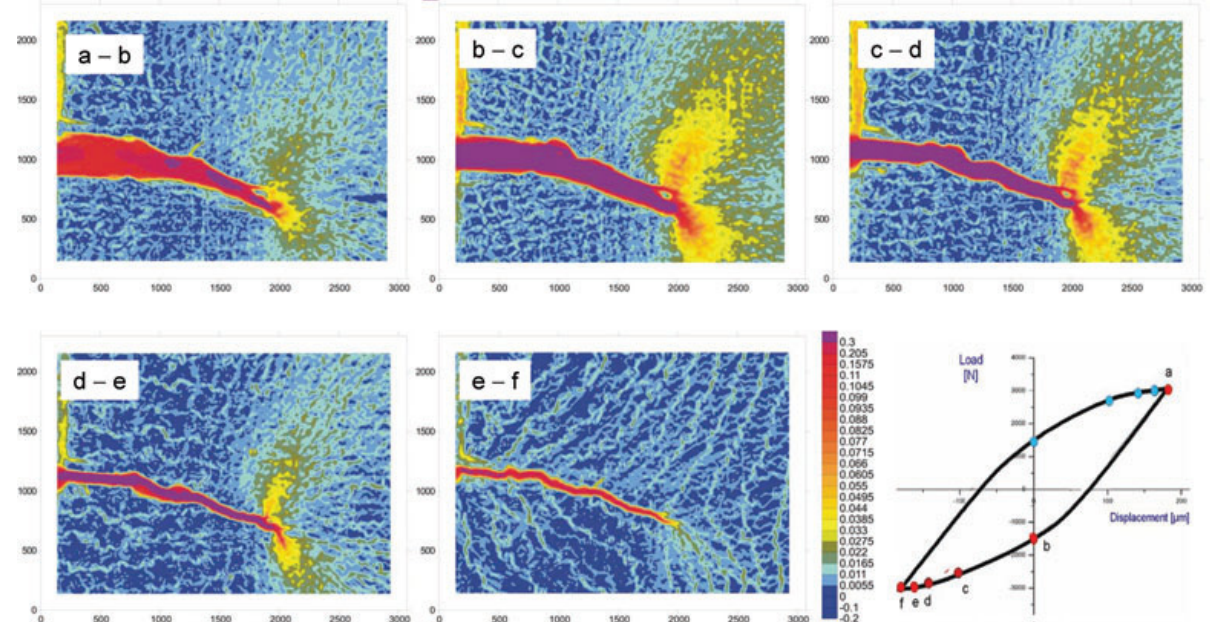

Figure 6: Incremental strain maps determined during unloading. The load increments are marked in the load cross head displacement curve. The change of the crack opening induces the apparent strain localization in the horizontal line in the midsection of the map. In front of the crack the typical strain distribution of crack is visible. The last strain map indicates that the contact of the fracture surfaces induces a disappearance of the characteristic crack tip deformation. For details of the determination of such maps see Refs [17, 24].

In the case of microstructurally short cracks, CTOD or $\triangle \mathrm{CTOD}$ values varies significantly between samples loaded with the same macro displacement and the same crack length. However, that is not surprising because for cracks smaller than the grain size the applied far-field $\Delta J$ or $\Delta J_{\text {eff }}$ do not describe solely the local driving force in such cases. A micromechanic approach is necessary (see, e.g. Ref. [24]), where the local microstructure has to be taken into account for a correct 
description of the driving force for crack propagation. The parameters to characterize the crack driving force in the different loading regimes are summarized in Fig. 9.
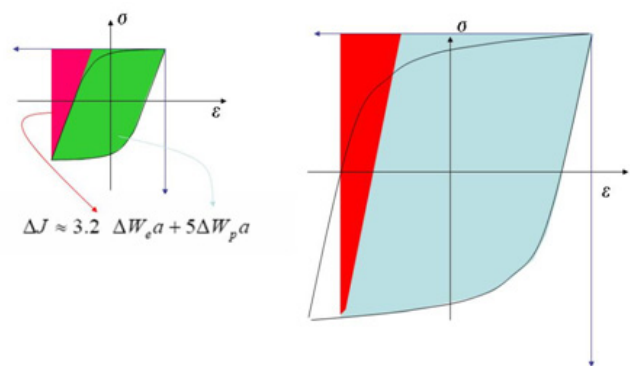

(a)

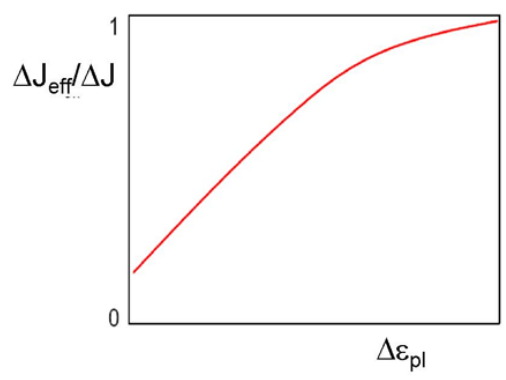

(b)

Figure 7: (a) illustration of the determination of the cyclic $J$ integral $\Delta J$ [25] for semi circular surface crack, and the necessary changes

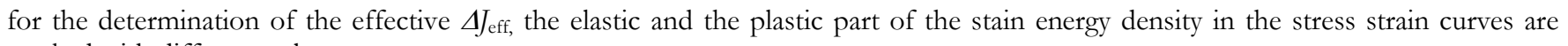
marked with different colours.

(b) Schematic illustration of the effective $\Delta J_{\text {eff }}$ as a function of the plastic strain amplitude.

LCF
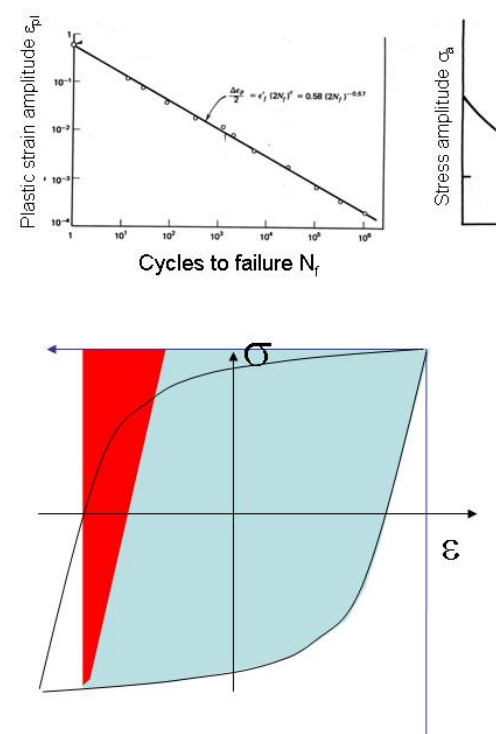

$\mathrm{HCF}$
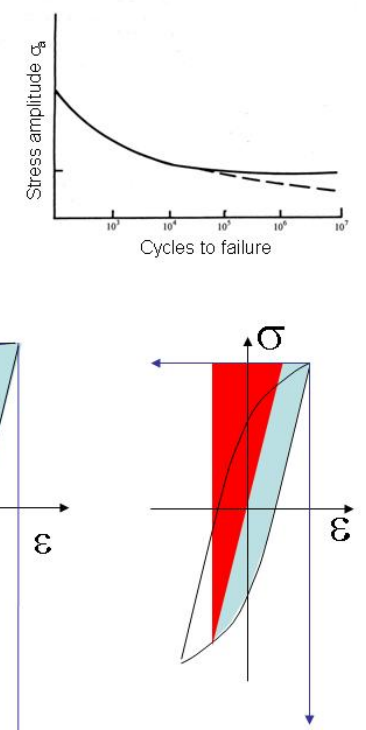

small scale yielding
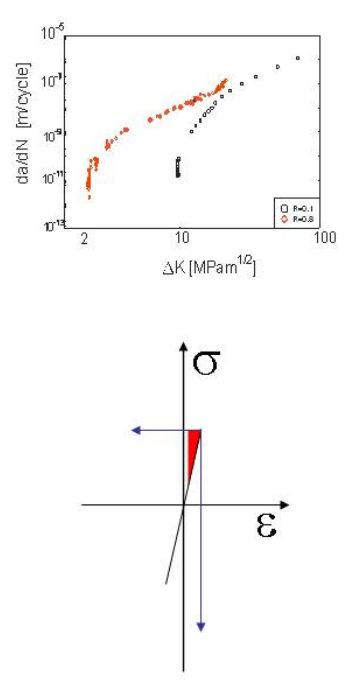

Figure 8: Schematic illustration of the determination of the effective driving force in the low cycle fatigue (LCF) regime, the high cycle fatigue regime (HCF) and the small scale yielding regime. The corresponding elastic and the plastic part of the stain energy density in the stress strain curves is marked with different colours

The main consequences from the presented LCF experiments and of the well documented phenomena under small scale yielding conditions - which can be considered as the two extreme cases in fatigue - can be summarized as follows:

- Crack closure is not only important to explain and predict the fatigue crack propagation under small scale yielding conditions, i.e. under linear elastic fracture mechanics, it is even as important in LCF and HCF.

- In LCF and HCF the complete strain amplitude is not responsible for crack propagation. The effective driving force for crack propagation should be $\Delta \mathrm{J}_{\text {eff }}$ or $\Delta \varepsilon_{\text {eff. }}$.

- The reduction of the effective driving force with decreasing strain amplitude is schematically depicted in Fig. 8. In the LCF region crack closure reduces predominately the effective plastic strain amplitude. In the HCF, the effective plastic and elastic strain amplitude is reduced.

- In LCF and HCF crack closure and crack opening load is different. For constant strain amplitudes, the closure strain and opening strain is equal, hence the effective strain amplitude is a better parameter than the effective stress amplitude. 
- In LCF and HCF crack closure is dominated by plasticity.

- Under mall scale yielding the roughness induced and the oxide induced crack closure is an additionally important mechanism controlling the crack closure load.

- The behaviour under variable amplitudes should be significantly different in LCF, HCF and small scale yielding.

- Overloads under small scale yielding have a beneficial effect on life time of a component due to an increase in the plasticity induced crack closure [18]. In the LCF and the upper HCF regime overloads should have a negative effect on life time, because the effective amplitude should be increased.

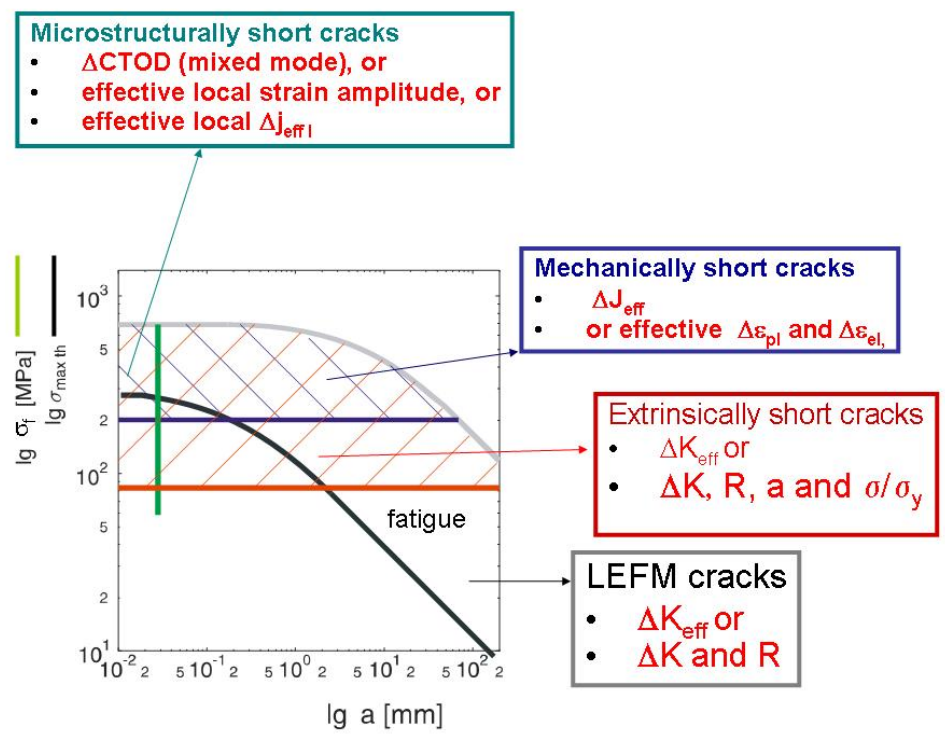

Figure 9: Illustration of the crack driving forces necessary to predict fatigue crack propagation for the different types of fatigue cracks. The crack lengths and loading regimes are indicated in the Kitagawa diagram.

\section{ConClusion}

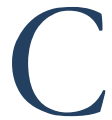
rack closure, which has been extensively investigated in the small scale yielding regime, is also important in the $\mathrm{HCF}$ and LCF regime. It significantly reduces the effective driving force, even in the LCF regime. The change of crack closure from LCF to small scale yielding is one of the key mechanisms to describe the complete spectrum of fatigue by a fracture mechanics methodology.

\section{REFERENCES}

[1] W. Elber, Engng Fract. Mech. 2 (1970) 37.

[2] H. Führing, W. Seeger, Engng Fract. Mech., 11 (1979) 99.

[3] B. Budiansky, N. Hutchinson, J. appl. Mech., 45 (1978) 267.

[4] R. C. McClung, Metall. Trans. A, 22 (1991) 1559.

[5] J. C. Jr. Newman, Mechanics of Fatigue Crack Closure, ASTM Special Technical Publication 768, Philadelphia, Pennsylvania: American Society for Testing and Materials, (1981) 53.

[6] R. Pippan, G.Strobl, H. Kreuzer, C. Motz, Acta Mater., 52 (2004) 4493.

[7] J. Pokluda, P. Šandera, R. Pippan, In: Fatigue 06, Edited by W. S. Johnson. Elsevier, Atlanta, Georgia, USA (2006) 0107A_03.

[8] J. Pokluda, R. Pippan, Mater. Sci. Eng., A462 (2007) 355.

[9] S. Suresh, Fatigue of materials. Cambridge University Press, Cambridge, UK, (1998).

[10] R. O. Ritchie, Mater. Sci. Eng., 103 (1988) 15.

[11] R. Pippan, F.O. Riemelmoser, H. Weinhandl, H. Kreuzer, Phil. Mag., 82A (2002) 3299. 
[12] R. Pippan, M. Berger, H. P. Stüwe, Metall. Trans., 18A (1987) 429.

[13] K. Tanaka, Y. Nakai, Fat. Engng, Mat, Struct., 6 (1983) 315.

[14] R. Pippan, Fatigue Fract. Engng Mater. Struct., 9 (1987) 319.

[15] F.O. Riemelmoser, P. Gumbsch, R. Pippan, Engineering Fracture Mechanics, 66 (2000) 35.

[16] S. Pearson, Engineering Fracture Mechanics, 7 (1975) 235.

[17] R. Pippan, C. Zelger, E. Gach, C. Bichler, H. Weinhandl, Fatigue Fract. Engng Mater. Struct., 35 (2011) 1.

[18] C. Bichler, R. Pippan, Eng. Fract. Mech., 74(2007) 1344.

[19] C. Zelger, In-situ Untersuchung des Wachstums kurzer Risse. Diplomarbeit, Montanuniversität Leoben (2007).

[20]J. Rice, Mechanics of Crack Tip Deformation and Extension by Fatigue. ASTM STP 415, Philadelphia, (1967) 247.

[21] S. S. Manson, National Advisory Commission on Aeronautics: Report 1170 Cleveland, OH (1954).

[22] L. F. Coffin, L. F. Trans. Am. Soc. Mech. Eng., 76 (1954) 931.

[23] A. Tatschl, O. Kolednik, Mater. Sci. Eng., A339 (2003) 265.

[24] N. E. Dowling, In: Cyclic Stress-strain and Plastic Deformation Aspects of Fatigue Crack Growth. Special Technical Publication 637 Philadelphia:American Society for Testing and Materials, (1977) 97.

[25] S. Suresh, R. O. Ritchie, Int. Metals Rev., 29 (1984) 445. 